\title{
The Expectation of TikTok in International Media: A Critical Discourse Analysis
}

\author{
Yumei Zhu \\ Sichuan University of Arts and Science, Dazhou, China \\ Email: jvj2008ns@hotmail.com
}

How to cite this paper: Zhu, Y. M. (2020). The Expectation of TikTok in International Media: A Critical Discourse Analysis. Open Journal of Social Sciences, 8, 136-148. https://doi.org/10.4236/jss.2020.812012

Received: November 11, 2020

Accepted: December 13, 2020

Published: December 16, 2020

Copyright (C 2020 by author(s) and Scientific Research Publishing Inc. This work is licensed under the Creative Commons Attribution International License (CC BY 4.0).

http://creativecommons.org/licenses/by/4.0/

\begin{abstract}
TikTok is a popular mobile video app used globally, which has aroused interests and disagreements among various stakeholders. However, in August 2020, President Donald Trump banned TikTok in the USA, relating to groundless national emergency claims. The executive order states that TikTok and its core technology will be banned within the next 45 days unless American companies take over the ownership before the due date. By using Critical Discourse Analysis, this paper examines international media's attitude of TikTok, and the government's expectation. Overall, international media's stance toward the ownership of TikTok and its valuable algorithm varies, but TikTok user's benefits are not concerned, and discrimination of the Chinese public and government still exists.
\end{abstract}

\section{Keywords}

TikTok, Critical Discourse Analysis, Media

\section{Introduction}

TikTok is a Chinese multi-national technology company headquartered in Beijing. It provides video-sharing social networking services, whose popularity is increasing rapidly, with over 500 million active users, and has been downloaded over eighty million times in the United States (InfluencerMarketingHub, 2020).

This August 2020, President Trump signed an executive order, in terms of a national threat, prohibiting the use of TikTok unless it could become a US Corporate entity within the 45-day period. American corporations such as; Microsoft, Oracle, and Walmart, are all interested in purchasing a portion of TikTok's operation or incorporating a new company within the US. Concerning the ban, TikTok has pleaded for a preliminary injunction, arguing the executive orders dramatically exceed the administrative power under US law. On the other hand, 
TikTok is actively discussing and working with interested American firms and endeavors to find a solution to satisfy the President's requirements. However, the issue is far more complicated than a business transaction or technology transfer. Oxford analysts (2020) describe that TikTok is in the middle of the China-US technology trade war, and the ownership of the valuable algorithm is the center of the TikTok deal. In addition, considering the fierce technology competition globally, international media (like BBC) describes the TikTok controversy as just an appetizer in the technology supremacy competition. Also, Scholars have criticized the executive order that has set a dangerous, anti-democratic example on how a government could groundlessly ban and control the way its people use the internet, and by doing so even without clear and extensive justifications (Koleson, 2020). Secondly, the imminent 2020 US Presidential election has postponed the TikTok ban hearing by Federal judge. It is widely believed that the outcome of the election could change how TikTok or the Trump administration approaches these proposals.

This paper will, however, examine the TikTok deal from a linguistic perspective, with six articles chosen from two internationally famous business newspapers: the Financial Times (short for FT), and the Wall Street Journal (short for WSJ).

Firstly, this paper will review the current literature regarding critical discourse analyses on business media discourse; secondly, examine how media represents attitudes and expectations of the interested parties namely; the original TikTok enterprise and its technology, the new TikTok global enterprise, Governments, and the TikTok users, with the use of modal verbs being analyzed in detail; finally, the social and geopolitical roots such as the China-USA relationship. Then, the China, American \& United Kingdom relationship will be analyzed to present how discourse reflects the social situation.

\section{Literature Review}

The literature focuses a lot on corporate discourse, such as sustainability reports (Higgins \& Coffey, 2016) annual reports (Fuoli, 2018) and corporate websites (Liu \& Wu, 2015). These research articles generally focus on how companies construct themselves in the current economic and political environment so as to influence the wider stakeholders. Critical discourse analysis is used to analyze news discourses. This methodology proposes to study the relations between social inequality, discourse, power, and dominance (Van Dijk, 1993). Using CDA, (Hirsto, 2011) examined every stock market discourse from media, finding that investing individual wealth management, devoid of broader social and political relevance, discourages social awareness with fair and sustainable market practices. In terms of the New Business Model (NBM), Hassanli, Small \& Darcy (2019), used CDA to examine the sharing of economy-Airbnb's representation in Sydney newspapers, concluding that the discourse of the new industry created a shared, welcoming form of hospitality. However, in many ways, Airbnb is seen as fitting the bill of "platform capitalism", and "techno-chauvinism". In other 
words, business media discourse, more or less, depends on their relative power, deciding who to quote in what context while reflecting their own view of the original text producers (Jacobs, 1999).

The current heavily debated TikTok issue, has drawn international media attention. Unlike previous media news reports, this issue attracted journalist from political, business, and technological environments, but there are few academic articles concerning TikTok's reports of discourse analysis.

The question of this paper is to investigate:

1) What is international media's attitude towards TikTok and the possible new Enterprise after Trump's Executive Order?

2) How did the international media use linguistic strategies to express its expectation of TikTok's future?

3) What are some of the social reasons that can be found to explain International media's TikTok expectation?

\section{Methodology}

Much of the public understanding of TikTok's potential security threat and the future ownership of TikTok International comes through the media, such as newspapers. To investigate how different media reports construct and deliver the TikTok threats or TikTok deals, this paper sources the media texts from two globally recognized newspapers, namely, Wall Street Journal and Financial Times.

The news material is collected randomly a few days before the deadline of TikTok Banning by the executive order. Debates over the validity of the Executive order and the fate of TikTok is the fiercest in this period. The genre of the articles is mixed. The following two tables (Table 1 and Table 2) illustrate the details of the articles For example, FT article No. 2; WSJ article No. 3 are news reports, and FT article No. 1 \& 3; WSJ article No. $1 \& 2$ are of editorial opinions.

Critical discourse analysis (CDA) is a trans-disciplinary field primarily concerned with the relationships between language use and social structure with its

Table 1. Financial times articles.

\begin{tabular}{|c|c|c|}
\hline \multirow{4}{*}{ FT } & Title & Issuing Date \\
\hline & 1) FT-TikTok deal hit by confusion over who will own and control the app & $21 / 09 / 2020$ \\
\hline & 2) FT-TikTok to be banned from US APP STORES FROM SUNDAY & $19 / 09 / 2020$ \\
\hline & 3) Ft-Trump's TikTok dance: the politicisation of American business & $19 / 09 / 2020$ \\
\hline
\end{tabular}

Table 2. Wall street journal articles.

\begin{tabular}{lc}
\hline \multicolumn{1}{c}{ Title } & Issuing Date \\
\cline { 2 - 2 } 1) TikTok's Zero Hour: Haggling with Trump, Doubts in China and a Deal & $22 / 09 / 2020$ \\
WSJ $\quad$ in Limbo & $21 / 09 / 2020$ \\
2) Trump, TikTok and Crony Capitalism & $21 / 09 / 2020$ \\
3) Trump signs off on TikTok deal with Oracle, Walmart
\end{tabular}


main aim to study how social power, domination and inequality are enacted, maintained and reproduced by texts (Fairclough, 2010, 2015). Discourse is the favoured vehicle of ideologies. Ideologies are the common beliefs and shared values of a group. Ideologies reside in discourse and discourse reflects the ideologies of a certain group. They serve to exercise and sustain power to define or unite a group. Although dominant discourses are naturalized by ideologies, a critical scrutiny of the discourses can help to make them transparent (Yu, 2019). This paper takes a critical perspective, with relation to the social justice concerns, endeavor to uncover the power relations and highlight whose interests are dominant in the two newspapers by unpacking and interrogation of the discourse. Shiller (2005) suggests that news media actively shape public opinion and play a large role in the propagation of public perception through feedback mechanisms and attention cascades. To provide a critical view regarding the issue of TikTok, the three-dimensional model of CDA, the Text, Discursive practices, and social practices employed to uncover the text of TikTok's future in the two newspapers presumably consumed by readers (Fairclough, 1993).

\section{Findings and Discussion}

\subsection{Analysis of the Written Text}

Fairclough (1989) defines text as a product rather than a process. For him, it was an extended way for the semiotic dimension of social events. The analysis of texts shows how texts articulate different discourses, genres and styles, potentially contributing to a changing character in the relation of social practices (Faiclough, 2002).

Such text analysis allows the analyst to access the relationship, tension and shifts between the order of discourse and networking related to social practices. This study focuses on identifying and detecting business media discourse of TikTok, and how media discourse tries to construct a picture of TikTok's future in the US. In the empirical analysis, the emphasis is put on the implicit and explicit ways of how the textual clues for underlying assumptions concerning, for instance, the uncertainties/speculations of the TikTok deal, socioeconomic environments, and conditions for possible investors are examined. As a result of the analysis, six different stakeholders are identified; TikTok and its technology, the new company-TikTok Global, the Chinese government, the US government, Interest parties (Oracle, Walmart, and Microsoft), and TikTok users.

In terms of business articles, they characterize it as a high frequency modal verb (Someya, 1999). This may be accounted for the fact that business articles are always concerned with future possibilities; uncertainty and speculation. By modal verbs, authors can explicitly state the probability of subjective (for example: I think) or objective (for example: it is likely); orientation. That is explicit (for example: it's likely that Mary knows), or implicit (for example: Mary probably knows); or the value that is attached to judgment: high (for example: must), median (for example: should) or low (for example: can) (Halliday \& Matthies- 
sen, 2004).

Both modality and modal auxiliaries express personal feelings, attitudes, value judgments and assessments, while this paper focuses on the use of modal verbs by six different parties. Modals, according to their meaning, are often classified as: possibility modals (can, may, might, could), necessity modals (ought, should, must) and predictive models (will, would, shall). Perkins (1983) classified modal verbs into primary and secondary modal, and his meaning classification is roughly as follows (Table 3 ).

This section firstly presents the overall quantitative finding of modal verbs for the whole text. Table 4 illustrates modal verbs in Financial Times articles, and Table 5 illustrates modal verbs in Wall Street Journal articles.

Table 3. Modal auxiliaries expressions.

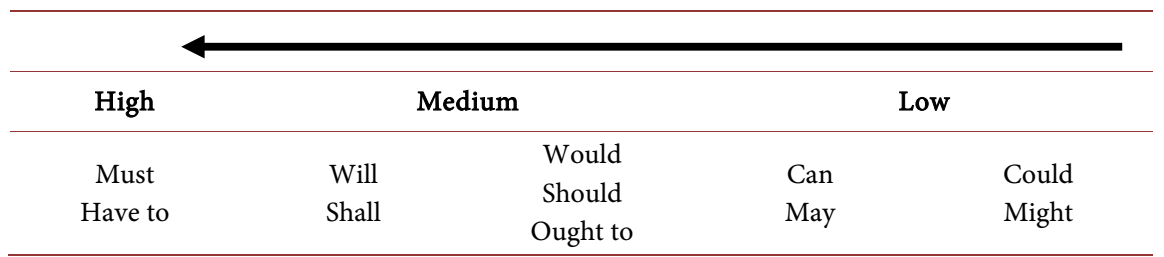

Source from: Modal Auxiliaries Expressions, Perkins (1983).

Table 4. Modal verbs in financial times.

\begin{tabular}{|c|c|c|c|c|c|}
\hline & High & \multicolumn{2}{|c|}{ Medium } & \multicolumn{2}{|c|}{ Low } \\
\hline & $\begin{array}{c}\text { Must } \\
\text { Have to }\end{array}$ & $\begin{array}{l}\text { Will } \\
\text { Shall }\end{array}$ & $\begin{array}{l}\text { Would } \\
\text { Should } \\
\text { Ought to }\end{array}$ & $\begin{array}{l}\text { Can } \\
\text { May }\end{array}$ & $\begin{array}{l}\text { Could } \\
\text { Might }\end{array}$ \\
\hline TikTok & & 3 & 9 & & 2 \\
\hline New TikTok company & & 1 & 18 & & 3 \\
\hline Chinese Government & & 2 & 3 & & \\
\hline US government & & & 6 & & \\
\hline Interest Parties & & & 1 & & \\
\hline TikTok User & & & 1 & & \\
\hline
\end{tabular}

Table 5. Modal verbs in wall street journal.

\begin{tabular}{|c|c|c|c|c|c|}
\hline & \multirow{2}{*}{$\begin{array}{c}\text { High } \\
\text { Must } \\
\text { Have to }\end{array}$} & \multicolumn{2}{|c|}{ Medium } & \multicolumn{2}{|c|}{ Low } \\
\hline & & $\begin{array}{l}\text { Will } \\
\text { Shall }\end{array}$ & $\begin{array}{l}\text { Would } \\
\text { Should } \\
\text { Ought to }\end{array}$ & $\begin{array}{l}\text { Can } \\
\text { May }\end{array}$ & $\begin{array}{l}\text { Could } \\
\text { Might }\end{array}$ \\
\hline TikTok & & 1 & 2 & 1 & 5 \\
\hline New TikTok company & & 7 & 7 & 3 & 7 \\
\hline Chinese Government & & 1 & 2 & 1 & \\
\hline US government & & & 3 & 1 & 2 \\
\hline Interest Parties & & 3 & 7 & 3 & 2 \\
\hline TikTok User & & & & & 3 \\
\hline
\end{tabular}


The overall distribution of modal verbs in WSJ (Table 4) is more diversified than FT (Table 5). Financial Times authors prefer secondary modals "would/should/ought to" than WSJ authors, while primary modals "can/may" are not used at all in FT; strong obligation modal verbs_-"must and have" are not used in both WSJ and FT. Authors of the two newspapers are most likely to express their degree of certainty/epistemic possibility of the New TikTok company.

In the six articles, almost half of them, use modal verbs to describe the possible future of the new enterprise; but how TikTok users may be influenced is of least concern. There are only four sentences that mentioned TikTok users. Interesting parties who are most likely to incorporate a new company or take over TikTok is another big concern within the articles. The two media use modal verbs differently. The FT mentions the possibility of purchasing TikTok by Microsoft only once; however, the WSJ predicts American giants (Oracle and Walmart) interest as much as 15 times, and with a strong will to emphasize the important role that the local American firm will play in the TikTok deal, in terms of ownership as well as the promise of user data security issues.

\subsection{TikTok and Its Technology}

Compared with "could and might", "would" tends to be more modal rather than other primary modals, used with a probability of around 70\% (Perkins, 1983; Someya, 2010). While, "might" is nearly always used as the conditional equivalent of "may" as a realization of epistemic modality-hypothesis (Perkins, 1983), or Hypothesis Marker (Someya, 2010) that indicates no significant change in the intended meaning. However, "will" as the primary modal verb, often expresses obligation, resolution (Traugott, 1972), volition and simple future prediction (Someya, 2010). In other words, the expectation of TikTok's actions or reactions in the FT is stronger than that of the WSJ.

1) ByteDance added that after raising funds ahead of a potential initial public offering, it would have an 80 percent stake in the company.-FT

2) A spokesman for TikTok guardian ByteDance Ltd. stated it $\underline{\text { might }}$ retain an $80 \%$ stake outright, whereas Oracle stated on Monday morning the $80 \%$ could be distributed proportionally to ByteDance's present shareholders, which embrace U.S. buyers.-WSJ

3) All the TikTok technology will be in possession of TikTok Global" but did not specify who would control it.-FT

4) August issued new restrictions on the export of artificial-intelligence technology, signaling that TikTok's core algorithms couldn't be included as a part of a deal.-WSJ

The four sentences above describe the future ownership of TikTok in the US, particularly the first two sentences, which discusses almost the same thing of who will own the $80 \%$ stake in the new company. The FT authors use "would" in the first sentence indicating a strong probability that the Chinese based technological firm will have a majority stake in the deal. However, the WSJ used 
"might", followed by "outright" and Oracle's contradictory statement to imply TikTok's majority possession in the new company is less likely to happen. In terms of the ownership of TikTok's most valuable asset-algorithms, the two media's attitudes vary. The use of "will" in the third sentence expresses a strong prediction that the algorithms belong to the new company, but it is still unknown who will indeed control the technology. However, the negation- "couldn't" in the fourth sentence denies any possibility that the core technology of TikTok could be in the new company's possession. If we trace back the actor of this impossibility, the author blames it on the new restriction issued in August by the Chinese government. However, there is no evidence that the Chinese authorities will restrict or try to ban any legal export of TikTok's intellectual property nor stop the transaction of the deal.

\subsection{The New "Global” TikTok Enterprise}

A large number of modal verbs are used to express the probable future of this new International version of TikTok. Once again, both of the newspapers heavily emphasize their concerns over the possibility of the new company's ownership, which is relatively the same result as discussed before. With the two media enterprises moderately predicting that the Initial Public Offering of the new company in the US, because so far it is still unknown whether the new company could get approved or not.

5) The new company would initially be majority owned by ByteDance, but would seek to list publicly in the US.-FT

6) Cfius pushed the group to agency up a dedication that TikTok would go public inside 12 months, to decide on its board...-WSJ

Even though, the new company has not received approval yet, there are a lot of discussions over how many new job opportunities the new TikTok may provide and how much tax it will be able to pay in the future. Comparatively, concerning the new company's possible contribution, it is difficult to make a conclusion on the outcome of the situation at hand, the FT expected lower than the WSJ. This can be found from the modal verbs used within the two media selected in example 7) "would", and example 8) "might", compared with "will" in example 9) and 10), which indicates a medium to high degree of volition that the new company will fulfill within the foreseeable future. Besides, example 9 and 10 provides precise data of: "25,000 jobs" and " 5 billion in tax collection". According to Van Dijk (1988), the rhetoric of news discourse forcefully suggests truthfulness by the implied exactness of precise numbers. In contrast to the Wall Street Journal, the Financial Times, to some extent is an outsider of the TikTok deal; and obviously, the WSJ expect, at least in these three articles, that the new technology company could stay and develop in the USA, by using strong volition modal verbs and precise numerical information to persuade the public to believe the benefits.

7) Mr Trump said the company would pay to finance an education fund as 
part of the deal.-FT

8) It said this was an estimate of the future taxes TikTok Global might pay, but the real amount would depend on the company's growth.-FT

9) The president said the agreement will result in the creation of 25,000 jobs, mostly in Texas...-WSJ

\subsection{Chinese and US Government}

Most predictions of government decisions over TikTok are quoted from other sources, namely, "the Commerce Department-Mr Munchin”, "Trump Administration", "Global Times", and Professional analyst-Feng Chucheng. Also, it is interesting to find that both FT and WSJ quoted the same statement from the "Global Times"

$\mathrm{Hu}$ Xijin, editor in chief of the International Instances, a Communist Get together-backed tabloid, stated Monday on Twitter he thought Beijing wouldn't approve the present settlement. He stated it "would endanger China's nationwide safety, pursuits and dignity." -WSJ.

Late on Monday (21st September 2020) in Beijing, the editor of China's state-affiliated Global Times said the Chinese government would not approve the current deal "because the agreement would endanger China's national security, interests and dignity"- $-F T$.

Compared with other quotations, the Global Times is neither an International influential newspaper like the WSJ or the FT, nor an official media enterprise like China Daily. In the quoted statements, the medium-level modal verb "would" has been used twice. Moreover, according to WSJ, the statement is from Hu Xijin's personal Twitter, not circulated newspaper. It is hard to explain why does such untrustworthy remarks are quoted by two International newspapers, but it is not hard to suggest that these two media companies used Mr. Hu's remarks to indicate a portion of Chinese governmental or public view over the TikTok deal which is wired and in fact not accepted at all among most a majority of the Chinese Public, within China.

Concern the execution order by the Trump Administration that will ban, and delay the banning of TikTok with the two newspapers almost expressing the same level of possibility. However, the guesstimate of the Chinese government's action can be found to be a very different picture in the eyes of these two newspapers.

By negation, sentence 11 straightly indicates that Beijing is unlikely to approve the export of TikTok technology, and the present continuous tense "rising" implies the American society increasingly believing that the Chinese government will intervene with the deal, which is obviously not supported by facts. In addition, sentence 12 is quoted from a China issue specialist, and provides a specific reason why Beijing is unlikely to intervene with the deal.

11) Contained in the administration, there was a rising realization that China

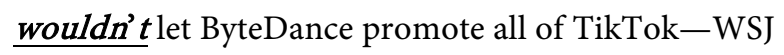


12) Feng Chucheng, an analyst at Plenum, a China-based risk consultancy, said Beijing would be unlikely to take a dramatic response at this point, because the US move was "limited".-FT

In a word, the international media's attitude toward TikTok and its interesting parties varied. The US media had a stronger will that TikTok and its valuable algorithm should be owned by a new US owned technology company, as it serves immediate benefits to the US society. While the UK media believes the opposite. It is uncertain that whether the new company will be incorporated or not. And even if the new firm is incorporated, the majority ownership belongs to the Beijing based parental company of TikTok. Concerning government's action, the two media agree that the banning and delaying of the ban of TikTok from the Trump administration is determined. But biased opinion over the Chinese government and the public opinion is still rooted. Finally, user benefits are the least concern of the two media, even though the banning could influence users most.

\subsection{Discursive Practice}

Discourse is socially situated, and it is a practice of how the texts are interpreted and received (Fairclough, 1993). To understand how and why the media reports the TikTok issue in this way or another, one firstly needs to study the purpose of journalism.

According to Richardson (2007), the aim of journalism is to enable citizens to better understand their lives and their position in the world. To fulfill this informational need requires "reporting the actions and activities of the powerful". In this regard, journalistic practice requires an analysis to examine the form and content of the message, the discourse procedures of production and consumption related to the message. As producers of newspaper's discourse have a considerable effect in what it is able to convey and the manner of how it is portrayed, thus, shaping social views (Shweinsberg, Darcy, \& Cheng, 2017).

In the present study, the function of journalistic discourse is to inform, guide and influence the readers and interesting parties of the current issue. The two newspapers have large International consumers, which are available to subscribe to in both online and print format. In other words, to ensure the subscription, consumers (probably business professionals) expecting more than informational content, they want personal views and professional opinions of the corporations and events they might have a stake in it. In addition, both papers are business and international oriented, but the Wall Street Journal is American based, while the Financial Times is British in origin, but the ownership transferred from Pearson (UK) to Nikkei (Japan) since 2015. Thus, it is not difficult to explain why WSJ have more content about American Firms-Oracle, Walmart, and Microsoft, and the expectations of a US-owned new TikTok is strong because this favors American readers. On the other hand, FT in nature is more international but it is hard to say FT's report is objective or not. As either a Chinese-owned or 
US-owned technology company serves interests to the UK or other international companies immediately.

\subsection{Social Practice}

The TikTok disputes reflect the increasing conflict between China and American. As Professor Samuel Huntington argues; China and the United States are fundamentally in conflict over ideologies and political and economic interests, which is impossible to improve. The end of the Cold War, the increasing interaction between Asia and America... and the relative decline in American power... other Asian societies and enabled the latter to resist American pressure.

The rise of China poses a more fundamental challenge to the United States. U.S. conflicts with China covered a much broader range of issues than those with Japan, including economic questions, human rights, Tibet, Taiwan, and the South China Sea, including weapons proliferation. On almost no major policy issue did the United States and China share common objectives (Huntington, 1996).

Since 2017, the trade war escalated from tariffs, Huawei, and Meng Wanzhou, to the banning of Chinese technology giants. The United States is attempting to exert hegemony ubiquitously, particularly the rising China technology innovation sections.

Two decades ago, the US defense department introduced a plan of "Joint Vision 2020", and "Full-spectrum dominance" being the key term in the plan. The term emphasizes the investment and development of new military capabilities, particularly the new technologies seen as a battlespace, which must be subject to U.S. dominance. In this regard, technology supremacy is one of American's most important national policies. From NASA to Silicon Valley, American institutes and firms lead to a world technology battlefield. However, challenges and disputes from the EU to Japan never ceased, while the rise of Chinese algorithms poses another threat to American's Full-spectrum dominance. That's why a strong expectation of the TikTok global can be found in WSJ, an ideology disregarding outside investors' and users' benefits, seriously undermines the international trade and investment system. Unfortunately, TikTok is just the beginning, and rumors about deeper inspection of Nasdaq listed Chinese technology companies, like Ali and Tencent Group is already popular. The future of rule-based international system is still under question.

After World War II, the US and the UK have enjoyed a truly "special relationship" (Foerser \& Raymond, 2017). The special points have culture, politics, and economic roots, but most importantly, due to links in three core areas: nuclear weapons, intelligence and Special Forces. However, the twin facts: Brexit and the advent of a nativist, protectionist, and isolationist US (Powell, 2016) had brought the special relationship to a crossroads. The British desired to play an enhanced global role, particularly by further trade liberalization, such as exercising greater influence on WTO policies (Zappettini, 2019), and strengthening 
its commitment to NATO (Foerser \& Raymond, 2017). In contrast, on the other side of the Atlantic, the US diverted its road: it pulls out of the Transpacific Partnership, withdraws from the Paris Agreement on climate change, renegotiates the NAFTA agreement, introduced a Trade War, and withdrew from WHO during the 2020 pandemic.

As the Foreign and Commonwealth Office stated in 2017, suggesting the UK-US relationship as:

"Our alliance with the United States remains our top priority and cornerstone of what we wish to achieve in the world." It has to be acknowledged that in some areas of foreign policy the current US Administration "has set new directions ... some of which differ from our own".

In terms of technological policies, unlike the United States' technology supremacy policy, the UK seeks to actively engage with technology companies and international partners in developing rules on cyber security and governance, while solving the challenge of attribution (House of Lords Report, 2018). Concerning the TikTok case, as an outsider, the UK media's attitude is somehow neutral; a US-owned TikTok does not serve their interest immediately, nor the current "politicized" TikTok deal under the Trump Administration, satisfying their expectation of acquiring this technology.

\section{Conclusion}

This research adds to the body of knowledge with regards to the business media discourse and conflicts of technology supremacy. The international media's attitude towards TikTok's ownership, its technology, and government decision varies. In terms of a new TikTok company, the US media expects higher than the UK media, as a new technology company serves immediate benefits, such as job opportunities, and tax to local government. While, FT believes the lion's share of the new TikTok and the core technology belongs to the startup company. Concerning government's actions there are both similarities and differences. Both media companies argue the banning or delaying of the ban on TikTok in App stores by the administration is determined. Over the Chinese government and public opinion, both of the media quoted Mr Hu's personal remarks on Twitter to reflect the Chinese opinion prejudicially. But unlike the US media, the FT argues that the Chinese government is less likely to intervene in an international business deal, with justifications provided by a China issue senior specialist to support the statement.

TikTok is simply a technology corporation, providing similar services like Facebook, Twitter, and Line (Japan), but it is obvious, the others never experienced similar prejudice as TikTok has. A widely held belief is that the US market is one of the freest markets to do business within the world, alongside democracy rooted in their DNA. However, a Chinese technological company finds groundless political intervention, an unstable playfield for companies wishing to do business in North America. It hurts TikTok users as well as in- 
nocent people who work for TikTok in the US. But what could be most detrimental is the rule-based international system where no one wants to trade under guns and cannons.

\section{Funding}

This work was supported by SASU's for Disciplinary Development [Grant Number: 2019XKQ006Y]

\section{Conflicts of Interest}

The author declares no conflicts of interest regarding the publication of this paper.

\section{References}

Fairclough, N. (1989). Language and Power. London: Longman.

Fairclough, N. (1993). Critical Discourse Analysis and the Commodification of Public Discourse. Discourse and Society, 4, 133-168. https://doi.org/10.1177/0957926593004002002

Fairclough, N. (2002). Language in New Capitalism. Discourse \& Society, 13, 63-166. https://doi.org/10.1177/0957926502013002404

Fairclough, N. (2010). Critical Discourse Analysis: Critical Study of Language (2nd ed.). London: Routledge.

Fairclough, N. (2015). Language and Power (3rd ed.). New York: Routledge.

Foerser, S., \& Raymond, R. (2017). The US-UK “Special Relationship” at a Critical Crossroads. Atlantic Council July (21).

Fuoli, M. (2018). Building a Trustworthy Corporate Identity: A Corpus-Based Analysis of Stance in Annual and Corporate Social Responsibility Reports. Applied Linguistics, 39, 846-885. https://doi.org/10.1093/applin/amw058

Halliday, M. A. K., \& Matthiessen, M. I. M. (2004). An Introduction to Functional Grammar (3rd ed.). London: Edward Arnold.

Hassanli, N., Small, J., \& Darcy, S. (2019). The Representation of Airbnb in Newspapers: A Critical Discourse Analysis. Current Issues in Tourism. https://doi.org/10.1080/13683500.2019.1669540

Higgins, C., \& Coffey, B. (2016). Improving How Sustainability Reports Drive Change: A Critical Discourse Analysis. Journal of Cleaner Production, 136, 18-29.

https://doi.org/10.1016/j.jclepro.2016.01.101

Hirsto, H. (2011). Everyday Discourses of Stock Market Investing: Searching for Investor Power and Responsibility. Consumption Markets \& Culture, 14, 57-77. https://doi.org/10.1080/10253866.2011.541176

House of Lords Report (2018). AI in the UK: Ready, Willing and Able? HOUSE OF LORDS Select Committee on Artificial Intelligence Report of Session 2017-2019. https://publications.parliament.uk/pa/ld201719/ldselect/ldai/100/100.pdf

Huntington, S. (1996). The Clash of Civilizations and the Remaking of World Order. New York: Simon and Shuster.

InfluencerMarketingHub (2020). What Is TikTok? What You Need to Know about the New Musical.ly. https://influencermarketinghub.com/what-is-tiktok/. 
Jacobs, G. (1999). Preformulating the News: An Analysis of the Metapragmatics of Press Releases. Amsterdam: Benjamins. https://doi.org/10.1075/pbns.60

Koleson, J. (2020). TikTok Is on the Clock, Will Democracy Stop? SLU Law Journal Online, 45.

Liu, M., \& Wu, D. (2015). Discursive Construction of Corporate Identity on the Web: A Glocalization Perspective. Intercultural Communication Studies, 24, 50-65.

Oxford Analysts (2020). TikTok Move Reveals Nature of US-China Tech Rivalry. Expert Briefings.

Perkins, M. (1983). Modal Expressions in English. London: Frances Pinter.

Powell, J. (2016). Britain’s Biggest Fear Realised-An Isolationist US President. http://www.theguardian.com/commentisfree/2016/nov/10/donald-trump-britain-great est-fear-isolationist-president

Richardson, J. E. (2007). Analysing Newspapers: An Approach from Critical Discourse Analysis. New York: Palgrave Macmillan.

Schweinsberg, S., Darcy, S., \& Cheng, M. (2017). The Agenda Setting Power of News Media in Framing the Future Role of Tourism in Protected Areas. Tourism Management, Elsevier, 62, 241-252. https://doi.org/10.1016/j.tourman.2017.04.011

Shiller, R. (2005). Irrational Exuberance (2nd ed.). Princeton NJ: Princeton University Press.

Someya, Y. (1999). A Corpus-Based Study of Lexical and Grammatical Features of Written Business English. Unpublished MA Thesis, Tokyo: The Graduate Department of Language and Information Sciences, The University of Tokyo.

Someya, Y. (2010), Modal Verbs and Their Semantic Functions in Business English. Aoyama Journal of Business (Aoyama Keiei Ronshu), 3.

Traugott, E. C. (1972). The History of English Syntax: A Transformational Approach to the History of English Sentence Structure. New York: Holt, Rinehart \& Winston.

Van Dijk, T. A. (1988). News as Discourse. Hillsdale, NJ: Lawrence Erlbaum Associates.

Van Dijk, T. A. (1993). Principles of Critical 2 Discourse Analysis. Discourse \& Society, 4, 249-283. https://doi.org/10.1177/0957926593004002006

Yu, Y. T. (2019). Media Representations of 'Leftover Women' in China: A Corpus-Assisted Critical Discourse Analysis. Gender and Language, 13, 369-395.

https://doi.org/10.1558/genl.36223

Zappettini, F. (2019). The Official Vision for "Global Britain": Brexit as Rupture and Continuity between Free Trade, Liberal Internationalism and "Values". In V. Koller, S. Kopf, \& M. Milgbauer (Eds.), Discourses of Brexit (pp. 140-154). Abingdon: Routledge. https://doi.org/10.4324/9781351041867-9 